\title{
Erken Bizans Dönemi Mimarisinde Az Bilinen Bir Düzenleme: Thalassidionlar
}

\author{
Gökçen Kurtuluş Öztaşkınª
}

\section{Özet}

Bizans Dönemi'nde su, dini metinlerdeki referanslara dayanılarak, yaşamın ve ilahi dirilişin kaynağı, kutsanma ve arınmanın sembolü olarak kabul edilir. Bu nedenle şifa/tedavi uygulamalarının yanı sıra liturjik kullanımlarda önemli bir unsur olarak karşımıza çıkar.

Thalassidionlar altarın altında ya da yakınında bulunan, bir su sistemiyle bağlantılı ve ayinlerden sonra liturjik objelerin yıkanması için kullanılan küçük boyutlu su hazneleridir. Son yıllarda yürütülen arkeolojik kazı çalışmaları sayesinde bilinen Erken Bizans Dönemi kiliselerinin sayısı artmıştır. Ancak kiliselerde tespit edilen düzenlemelerin su kültü ile ilişkisi kurulsa da nasıl bir işlevle kullanıldıkları sorusu varlığını sürdürmektedir. Bu nedenle makalede kiliselerde suyun kullanımı açıklanarak bunlar arasında önemli bir yere sahip Thalassidion düzenlemelerinin ayrıntılı olarak tanıtılması amaçlanmıştır.

Tespit edilen Thalassidion örneklerinin düzenlemeleri birbirlerinden farklıdır. Konum, biçim ve su sisteminde ortak özellikler görülmez. Kuyu, kanal ve künk sistemleri sayesinde bazı kiliseler için thalassidion bulunduğuna dair öneriler getirmek mümkündür. Mimari verilere göre Kıbrıs, Kudüs, Kuzey Afrika ve Yunanistan'da birer örnek; Anadolu'da ise beş örnek tanımlanmıştır.
Anahtar Kelimeler

Bema

Altar

Liturji

Kutsal Su

Makale Hakkında

Geliş Tarihi: 16.01.2020

Kabul Tarihi: 13.03.2020

Doi: $10.18026 /$ cbayarsos.676310

\section{A Recondite Arrengement in the Early Byzantine Architecture: Thalassidia}

\begin{abstract}
In the Byzantine period, water is regarded as the source of life and divine resurrection, a symbol of blessing and purification, based on references in religious texts. Therefore, in addition to healing/therapeutic applications, it is an important element in liturgical use.

Thalassidia are small water reservoirs connected to a water system under or near the altar, used for ceramonial washing. On account of the excavations carried out in recent years, the number of recognised churches belong to Early Byzantine has increased. Even though the arrangements determined in the churches are related to water cult, the functional proposals are determined according to general information. Therefore, in this article, aimed to introduce the usage of water in churches and to explain Thalassidion in detail.

The elements determined as Thalassidia are arrenged differently from each other. Location, shape and water system do not have common features. It is possible to propose thalasidion for usage in churches through well, canal and pipe systems. According to the architectural data, there are thalassidia at Cyprus, Jerusalem, North Africa and Greece; five examples have been defined at Anatolia.
\end{abstract}

Keywords

Bema

Altar

Liturgy

Holy water

\begin{tabular}{r} 
About Article \\
\hline Received: 16.01 .2020 \\
Accepted: 13.03 .2020
\end{tabular}

Doi: $10.18026 /$ cbayarsos.676310 


\section{Giriş}

Su, her dönemde insanlar tarafından spiritüel anlamlar yüklenerek kutsanma ve günahlardan arınmanın sembolü olmuştur. Hristiyanlık'la beraber su, İncil ve Tevrat'taki referanslara dayanılarak, yaşamın ve ilahi dirilişin kaynağı olarak kabul edilmiştir. Buradan hareketle liturjik ve şifa amaçlı kullanımlarda önemli bir unsur olarak karşımıza çıkar.

Bizans dönemi mimarisinde, suyun kutsalllık atfedilerek kullanımı çeşitlilik gösterir. Ancak, tespit edilen mimari düzenlemelerin tanımlanmasında eksiklikler ve/veya farklılıklar göze çarpar. Ayrıca, suyun yaşam için vazgeçilmez niteliği ve gündelik işlerdeki yaygın kullanımı, seküler nitelikte düzenlemelerin kutsal ile ilişkilendirilmesine neden olmaktadır.

Thalassidion ${ }^{1}$, ökaristi esnasında kullanılan objelerin yıkanması için düzenlenmiş ve genellikle altar yanında yer alan, küçük boyutlu su haznesidir. Konu ve örnekler sadece tek bir yayında

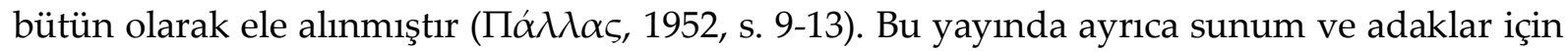
kullanılan mezar bağlantılı çukurlar da "bothros tipi thalassa" olarak adlandırılarak yayına dâhil edilmiştir².

Erken tarihli bu yayından sonraki bulgular ${ }^{3}$ ve yeni örnekler konunun yeniden ele alınmasını gerekli kılar. Son yıllarda artan ilgiyle beraber Erken Bizans dönemi kiliselerinde yürütülen arkeolojik kazı çalışmalarının çoğalmasıyla beraber kiliselerde tespit edilen su kültü ile ilgili düzenlemelerin işlevlerinin tanımlanması yararlı olacaktır. Bu nedenle aşağıdaki satırlarda öncelikle suyun kutsal niteliğine bağlı olarak Bizans Dönemi'ndeki kullanımı ele alınmış ve bunlar arasından thalassidion düzenlemelerinin ayrıntılı olarak tanıtılması amaçlanmıştır. Ayrıca bazı kiliselerdeki düzenlemelerin thalassidion olarak tanımlanabileceğine yönelik öneriler getirilmiştir.

\section{Bizans Mimarisinde Suyun Kutsal Niteliğine Bağlı Olarak Kullanımı}

Tevrat'ta yaratılışın en başında yeryüzü sularla kaplıdır ve Tanrı'nın ruhu bu suların üzerinde dolaşır (Tekvin 1: 1-2). Tanrı "yaşam çeşmesi" olarak ifade edilir (Mezmurlar: 36: 8-9). Paralel bir şekilde İncil metinlerinde de su sonsuz yaşamın kaynağı olarak gösterilir (Vahiy: 21-6; Yuhanna 4: 14).

Su, bu sembolik anlamları ve özellikle günahlardan arınmanın bir vasıtası olarak görüldüğünden liturjiye dâhil edilmiştir. Bunun yanı sıra, tedavi amaçlı uygulamalar söz konusu olduğunda, suyun kutsal niteliğine bağlı olarak şifa kaynağ Bizans Dönemi'nde şifanın, hekimler tarafından tıp ilmiyle sağlanmış olması ya da kutsal niteliklere bağlı olarak kazanılması arasında bir ayrım yoktur. Şifa bulmak çoğunlukla azizmartyr kültüne bağlı ortaya çıkan bir mucize olarak kabul edilir (Pitarakis, 2015, s. 42).

Bu açıdan bakıldığında Bizans döneminde suyun kutsal niteliğine bağlı olarak kullanımını "Şifa Amaçlı" ve "Liturjik İşlevli" olarak iki grup altında toplamak mümkündür.

\section{Şifa Amaçlı Kullanım}

Suyun şifa kaynağı olarak kullanıldığı yapılar hagiasma, lousmata ve locus-sanctuslardır.

Ayazmalar (hagiasma), kutsal kabul edilen ve şifalı olduğuna inanılan ya da sonradan kutsanan su kaynakları üzerine inşa edilmiş yapılardır. Genellikle bir kiliseyle birlikte inşa edilmiş yapılar olmakla birlikte, müstakil olarak planlanmış örnekler de mevcuttur (Karakaya, 1993, 472). Küçük boyutlu ve basit planlı yapılardır. Kaynak suyunun kullanımı için yapılmış havuz ya da tekne mekânın ana unsurudur (Çelebi, 2018, 31). 
Ortodoks Hristiyanlık'ta bir tedavi esnasında kullanılan sudan kaynaklanan şifanın bir aziz ya da azizenin mucizesi olarak kabul edilmesi yaygındır. Bu nedenle hastaların tedavileri esnasında yıkanmaları için kullanılan ritüel hamamları "Lousmata" olarak adlandırılır (Berger, 1982, 79; Pitarakis, 2015, 45). 5. yüzyıldan itibaren hamamlar piskoposluklara bağlı hayır kurumları aracılığıyla yönetilmeye başlanmış ve böylece çoğu hamam hastanelerin bir parçası durumuna gelmiştir. Dolayısıyla yazılı bir metin olmadan hamamlardaki suya kutsal nitelik atfedilip edilmediğini saptamak mümkün değildir (Magdalino, 1990, s. 166-168).

Şifa verme niteliğine sahip kutsal alanlar olarak ele alınabilecek locus-sanctuslar, özellikle Tevrat ve İncil'de adı anılan bazı kutsal alanlarda ya da aziz/martyr kültüne sahip yerleşimlerde yer alır. MS. 4. yüzyıl ve sonrasında hacılığın yaygınlaşmasıyla beraber bu merkezlerin kalabalık ziyaretçi akınına uğradığ1 anlaşılır (Vikan, 1991, s. 1244). Locussanctuslarda elde edilen ve eulogia adı verilen su, yağ, toprak gibi şifa veren malzemeler ampulla ya da unguentarium adı verilen küçük kaplara konularak ziyaretçilere verilirdi (Talbot, 2002, s. 159-160; Caseau, 2007, 644-645). İsa'nın felçli hastayı iyileştirme mucizesini gerçekleştirdiği Beytesta Havuzu (Yuhanna 5: 2-9) ve körün iyileşmesini sağladığ Havuzu (Yuhanna 9: 1-11) kutsal topraklarda şifanın su ile ilişkili olduğu locus-sanctuslardır. Diğer bölgelerden Selanik Aziz Demetrios (Bakırtziz, 2002, s. 185-186), Menautsis Azizler Kyros ve Ioannes (Montserrat, 1998, s. 258), Honaz Başmelek Mikhael ve Yalova Pythia Thermae (Foss, 2002, s. 143) su kültüne sahip önemli merkezler olarak sayılabilir. Locussanctusların mimari düzenlerinde ortak ve belirleyici özelliklerle karşılaşılmaz. Kilise ya da manastır merkezli kuruluşlarda ziyarete gelen kitleler için konaklama birimleri, bakım evleri ve hamamlar yer alır. Birimler her merkezde yoğunluğa bağlı olarak farklı düzen ve boyuttadır.

\section{Liturjik İşlevli Kullanım}

Bizans mimarisinde baptisterion, phiale, louterion, mandatum, kolymbion ve thalassidionlar suyun liturjik işlevle yer aldığı unsurlardır. Liturjik kullanım açısından değerlendirildiğinde en yaygın yapı grubunu vaftizhaneler (baptisterion) oluşturur. Vaftiz, günahkâr bir doğayla yeryüzüne gelen kişilerin günahlarının affedilmesi (arınma) ve su aracılığılla yeni bir hayata başlamasının (kutsanma) sembolüdür (Yuhanna 3: 3-8; Romalılar 6: 3-7; Koloseliler 2: 12; 1. Petrus 3: 21). Bizans liturjisinde vaftizin ardından krismasyon denilen yağlanma töreni yapılır. Krismasyon kişinin Kutsal Ruh ile yeniden doğduğunun mührüdür (McCormick, 1991, s. 107). Böylece kiliseye kabul edilen kişi ökaristi ayinine katılarak ilk komünyonunu alır (Taft, 1991a, s. 491). Vaftizhanelerin plan ve konumları açısından genel bir ilke yoktur; kiliselerle bağlantılı ya da bağımsız birimler olarak inşa edilmiş olabilirler. En yaygın olarak kullanılan plan tipi dikdörtgendir (Khatchatrian, 1982, 15-41; Ristow, 1998, 16-19). Vaftizin ölüm ve yeniden doğuş ile olan sembolik ilişkisi nedeniyle mezar mimarisinin örnek alınması Erken Bizans Dönemi'nde merkezi planlı vaftizhanelerin ortaya çıkmasına neden olmuştur. Bunlar arasında kutsal sekiz sayısını sembolize eden oktogon planlı örnekler yaygındır (Aydın, 2006, s. 1-4).

Phialeler kiliseye girmeden önce ellerin yıkanması için yapılmış çeşme ya da havuz biçimli kuruluşlardır. Kutsal bir alana girmeden önce ellerin yıkanması Arkaik dönemden itibaren Akdeniz çevresinde karşılaşılan bir gelenektir. Bu eylem günlük bir temizliğin ötesinde ruhun temizlenmesi, arınması ile ilişkilidir (Yazıcı, 2018, s. 22-26). Hristiyan kullanımında ilk olarak Eusebius tarafından Tyre kilisesi anlatılırken söz edilir (Eusebious X.IV.39-40). Genellikle çokgen planlı ve baldaken şeklinde örtülü örnekleri bilinmektedir. Yazılı kaynaklardan Roma Aziz Petrus ve İstanbul Ayasofya kiliselerinin atriumlarında zengin süslemelere sahip birer 
phiale bulunduğu anlaşılır (Broilo, 2009, s. 9-14). İstanbul'da MS. 5. yüzyil ortalarına tarihlenen Studios Manastır Kilisesi ve Topkapı Sarayı Bazilikası'nın phialeleri çokgen planlıdır (Mathews, 1971, s. 21, 35). Demre Aziz Nikolaos Kilisesi atriumunda yer alan çokgen planlı havuz biçimindeki phiale yapının 6. yüzyıla tarihlenen evresine aittir (Doğan, 2019, s. 32).

Epifani (epipháneia) yortusunda suların kutsanması için kullanılan hazneler Louterion (ya da Loutron) olarak adlandırılır. Derin kap formundaki taş eserlerin ortak özelliği alt kısımlarında su çıkışı için bir oluk bulunmasıdır. Boyutları ve basamaklara sahip olmamalarıyla vaftiz teknelerinden farklılaşırlar. Yazıt tespit edilen örneklerde su ile ilişkili Tevrat alıntılarıyla

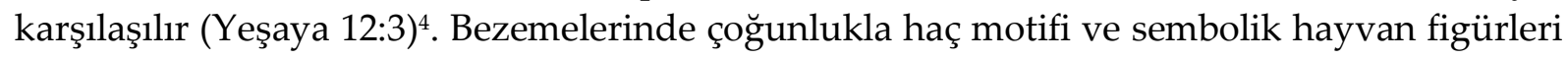
tercih edilmiştir. Biçimsel uygunlukları nedeniyle sütun başlıklarının oyularak ikincil kullanımda louterion olarak işlevlendirilmeleri yaygındır (Ruggieri, 2017, s. 309-315).

Phialeler MS. 6. yüzyıldan itibaren suların kutsanması törenlerinde de kullanılmışlardır (Bogdanovic, 2017, s. 373). Ayrıca Orta Bizans döneminde çocuk vaftizlerinin yaygınlaşmaya başladığı görülür. Bu nedenle su haznelerinin işlevini belirlemek için (vaftiz kabı, phiale ya da louterion) ait oldukları yapıla beraber konum, boyut ve dekorasyon gibi özelliklerinin birlikte ele alınması gerekir. Yazılı kaynaklarda da özellikle phiale ve louterion ayrımı konusunda karışıklıklar söz konusudur (Teteriatnikov, 1996, s. 95-108).

Genellikle kilise girişlerinde yer alan nişlere yerleştirilmiş su hazneleri biçimindeki düzenlemeler kolymbion olarak adlandırılır. Naosa geçmeden önce ellerin suya daldırılarak istavroz çıkartılması kiliseye temizlenmiş ve arınmış olarak girmeyi sembolize eder. Haznelerde kutsanmış su olduğu düşünülür. Suriye ve Kilikya bölgelerindeki Erken Bizans Dönemi yapılarında örnekleriyle karşılaşılır (Aydın, 2012, s. 417).

Mandatum olarak adlandırılan ayak yıkama havuzları, Paskalya yortusu öncesindeki Kutsal Perşembe günü piskoposların papazların ayaklarını yıkaması için kullanılır. İncil'de İsa'nın Son Akşam Yemeği'nden sonra havarilerinin ayaklarını yıkaması (Yuhannna 13: 4-17) nedeniyle alçakgönüllüğü vurgulamak için yapılan bir seramonidir. Mısır' da iki yapıda tespit edilen örnekler naosun batısında yer alan dikdörtgen planlı alçak havuzlar şeklindedir. Bu tören için çoğunlukla taşınabilir su haznelerinin kullanıldığı düşünülmelidir (Grossmann, 2001, s. 196).

\section{Thalassidionlar}

Liturjik işlevli kullanılan diğer bir düzenleme ökaristi ayini sonrasında törensel yıkamalar için

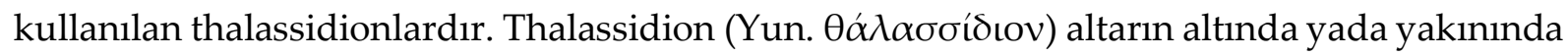
bulunan küçük boyutlu su haznesidir. Genellikle bir su sistemiyle bağlantılı bu düzenlemeler ayinlerden sonra liturjik objelerin yıkanması için kullanılır (Taft ve Bouras, 1991, s. 71; Doğan, 2001, s. 34).

Ökaristi ayininin iki aşamasında su kullanılır. İlk olarak Proskomidie olarak tanımlanan ekmek ve şarabın hazırlanması esnasında, şarap içime uygun hâle getirilmek üzere sulandırılır. Komünyon olarak adlandırılan ekmek ve şarabın dağıtımı öncesinde rahiplerin elleri yıkanır. $\mathrm{Bu}$ işlem için ibrik ve trulla kullanılır. Anaphora ${ }^{5}$ esnasında da şaraba sıcak su katılır (Acara, 1998, s. 189). Ökaristi ayininden sona ise altar ve kullanılan liturjik eserlerin temizliği yapılır. Papazlar tarafından yapılan bu işlemin liturjinin bir parçası olarak algılandığı anlaşılır. Ancak

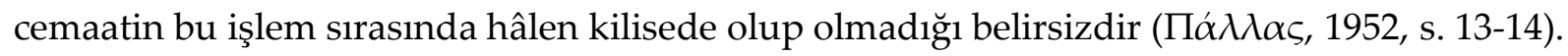
Orta Bizans Dönemi'nde değişen liturjiyle birlikte thalassidionlar kiliselerin köşe odalarında 
tahliye sistemine bağlanmış küçük hazneler ya da çeşmeler olarak varlığını sürdürür. Ancak sınırlı sayıdaki kilisede tespit edilmiştir (Altripp, 2000, s. 68).

Erken Bizans Dönemi'ne tarihlenen Cezayir Kasr-El-Kelb Kilisesi, Yunanistan Afentelli Kilisesi, Kudüs Haç Manastırı, Kıbrıs Kourion Piskoposluk Kilisesi, Anadolu' da ise Labraunda Doğu Kilisesi, Ksanthos Doğu Bazilikası, Laodikeia Kilisesi, Aphrodisias Kathedral Kilisesi ve Patara Kent Bazilikası'nın thalassidion düzenlemesine sahip oldukları anlaşılmaktadır. Bu örneklerin yanı sıra yazılı kaynaklardan İmparator I. Iustinianus'un İstanbul Ayasofya Kilisesi'ne değerli taşlarla bezenmiş bir thalassidion hediye ettiği anlaşılır. 13. yüzyıl başında kiliseyi ziyaret eden Antoine de Novgorod sunağın yanında akan sulardan söz eder. Bu sular olasılıkla kilise altındaki sarnıçtan thalassidiona geliyor olmalıdır. Ancak düzenlemenin biçimi ve konumu kesin olarak bilinmemektedir (Ebersolt, 1910, s. 11, dn. 2).

Kasr-El-Kelb Kilisesi'nde (Tebessa-Meskiana) Aziz Marculus kutsal alanının önündeki altarın bir thalassidiona sahip olduğu tespit edilmiştir (Şekil 1-2). Üç nefli kilisenin apsis alanında çok sayıda mezar bulunur. Güney nefin doğu ucundaki köşe odasında da Aziz Marculus'un rölikleri yer alır. Kilisenin bemasını sınırlandıran parapetler güney nefe doğru ilerletilmiştir. Bu alanda Aziz Marculus'a adanmış bir altar ve altarın batısında bir thalassidion yer alır. Thalassidion dört levhayla çevrelenmiş küresel gövdeli bir su haznesi biçimindedir. Mermer

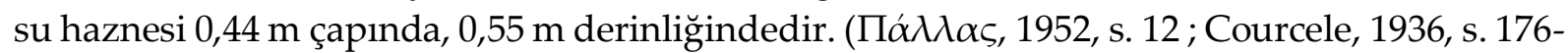
178).

Afentelli Kilisesi'nde (Lesvos-Skala Erosou) yapılan kazılarda altarın güneyinden bir su haznesi ele geçmiştir (Şekil 3-4). 0,60 m çapında ve 0,18 m derinliğindeki haznenin 0,50 m yüksekliğindeki yivli bir sütun üzerine yerleştiği anlaşılır. Parçalar devşirmedir. Mozaik döşemelerde kesinti gözlenmemesi nedeniyle taşınabilir bir parça olarak kullanıldığı anlaşılır

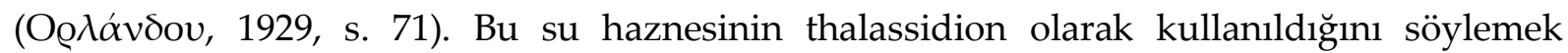

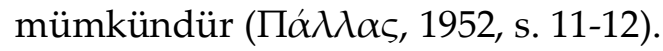

Haç Manastırı (Batı Kudüs) MS. 11. yüzyildan itibaren Gürcü cemaati tarafından kullanılmaktadır. Kilisede yapılan kazı çalışmalarında yapının ilk evresinde MS. 5. yüzyıl başlarında bir Bizans kilisesi olarak inşa edildiği ve İslam fetihlerinin ardından terk edildiği anlaşılmıştır. Kilisenin ilk evresinde altarın doğusunda yer alan bir thalassidion tespit edilmiştir (Şekil 5). Thalassidion dairesel planlı bir hazne biçimindedir (Tchekhanovets, 2018, s. 173-176).

Kourion Piskoposluk Kilisesi'ninde (Kıbrıs-Limasol) 1935 yılında yapılan kazı çalışmalarında, bemanın güney batısında taş örgü bir çukur tespit edilmiştir (Şekil 6). Örgünün sağlam olmaması ve tehlike yaratabileceği düşünüldüğü için duvarları sökülmüsştür. Bir kenarında stylobata yaslanan çukurun ağız kısmı kesmetaşlarla çevrilidir. Çukur, konumu nedeniyle kutsal objelerin yıkandığı bir thalassidiona ait olmalıdır (Megaw, 2007, s. 5-6). Kilisenin bema düzenlemesinde altarın bulunduğu alan ile presbyterium ${ }^{6}$ arasında bir basamakla yükseltilmiş kademeyle ayrım yapılmıştır. Thalassidion altarın yer aldığı alanın güneybatı köşesinde yer alır. Kilisenin plan çizimlerine bakıldığında thalassidion çukurunun yaklaşık $0,60 \times 0,80 \mathrm{~m}$ ölçülerinde dikdörtgen planlı olduğu anlaşılır.

Labraunda (Muğla-Milas) Doğu Kilisesi apsisinde batı-doğu yönelişli bir kanal tespit edilmiştir. Kilisenin batısından başlayan bir künk sistemi ile kanala kadar su getirildiği anlaşılmaktadır (Şekil 7-8). Kanal apsis duvarının doğusundan dışarıya çıkarak güneye yönelir. Kanalın apsis içerisinde yaklaşık 1 m'lik kısmının kaplama yapılmadan üstü açık 
kalacak şekilde düzenlendiği anlaşılmaktadır. $0.20 \mathrm{~m}$ genişliğindeki kanal batıda $0.30 \mathrm{~m}$, doğuda 0.60 m derinliktedir. Kanal mermer kaplamalı ve su geçirmez nitelikte yapılmıştır. Künk sisteminden gelen suyun baskısı nedeniyle buluntular doğudaki çıkışta birikmiş durumda tespit edilmiştir (Blid, 2012, s. 193-199). Kanal içerisinden ele geçen buluntular arasında cam eserler yoğundur. Parçaların kupa, bardak ve kandillere ait olduğu anlaşılır. Buluntulara dayanılarak düzenlemenin ayazma olabileceği düşünülmüştür (Blid, 2009, s. 137139). Ancak özellikle Ksanthos bulgulariyla yeniden ele alınarak thalassidion olarak tanımlanmıştır (Blid, 2012, s. 255). Ayazmalarda temel unsurun su ve ziyaretçiler ilişkisi olduğu düşünüldüğünde bema ayazma işlevi için uygun değildir. Bizans Dönemi kiliselerinin bema kısmında yer alan başka bir ayazma örneği de bilinmemektedir.

Ksanthos (Antalya-Kınık) Doğu Bazilikası'nda orta nef stylobatları arasında uzanarak bemanın içinden geçen bir künk sistemi tespit edilmiştir (Şekil 9). Kot seviyelerine göre kanalın akış yönü kuzeyden güneye doğrudur. Ancak kilisedeki Orta Bizans Dönemi yapılaşmasında tahrip olması nedeniyle devamı izlenemez. Künk sistemi kuzeyden gelerek altar kaidesinin kuzeydoğu köşesine ulaşır ve güneydoğu köşesinden güneye doğru devam eder. Altar kaidesinin doğu kenarı altında da gözlenen künk sisteminin, hattı birleştirdiği ancak kaymış olabileceği düşünülür. Orta Bizans Dönemi yapılaşmasında zemin yaklaşık 0,10 m yükseltilerek kullanılmıştır. Künk sistemindeki kayma bu dönemde meydana gelmiş olmalıdır. Kilisenin altar kaidesi 3.10x1.90 m ölçülerinde ve mermer kaplıdır. Kaidenin ortası dişta 0.60 m genişliğinde çerçeveyle sınırlanan $0.23 \mathrm{~m}$ derinliğinde bir hazne biçimindedir (Des Courtils ve Laroche, 1999, s. 388). Altarın doğu kenarıyla bağlantılı su sisteminin liturjik bir kullanım için düzenlendiği anlaşılır. Hazne biçimli altar kaidesi de ele alındığında thalassidion olarak tanımlamak mümkündür.

Laodikeia Kilisesi (Denizli-Goncalı) kazılarında altarla bağlantılı bir künk sistemi tespit edilmiştir. Kilisenin güneyindeki su terminalinden başlayan künk sistemi, altarın doğu kenarından dikey yönde dışarı çıkarak altara su sağlamaktadır. Altarın batı kenarındaki gider sayesinde yine güney yöne doğru su tahliyesi sağlanmıştır. Dikdörtgen planlı altar kaidesi alçak bir havuz biçiminde düzenlenmiştir (Şekil 10-12). Kazı çalışmalarında ele geçen küresel gövdeli mermer kabın su sistemine ait olduğu anlaşılır ((Şekil 18). Kabın ağız kenarında “...ve onun tüm ailesi ve kendisi için bir adak olarak..." ifadesi okunmaktadır. Su sisteminin hacılara kutsal su dağıtmak için kullanıldığı düşünülür (Şimşek, 2015, s. 42-44). Su sisteminin altarla ilişkisi, altar kaidesinin hazne biçiminde oluşu ve mermer su kabı birlikte ele alındığında tüm düzenleme thalassidion olarak tanımlanmalıdır.

Aphrodisias Kathedral Kilisesi'nde (Aydın-Geyre) bema merkezinde moloztaştan örülmüş bir kuyu yer alır (Şekil 13-14). Kuyu taşlarının üst seviyeleri bema zeminiyle aynı seviyededir. Üzeinde 0,80 m çapında, sütun kaidesinden oyulmuş bir bilezik taşı yer alır. Kuyunun etrafındaki sütun kaideleri kyboriona aittir. Kuyu altarın doğu kenarı hizasında apsis aksında bulunur (Hebert, 2000, s. 43). Kazı çalışmalarında kuyu içinden sadece Bizans Dönemi'ne tarihlenen buluntular ele geçmiştir. Kuyunun konumuna göre, kilisenin yerleştiği alanda bulunan Aphrodite Tapınağı'nın dışında ancak temenos sınırları içinde yer aldığı anlaşılır. Bizans Dönemi'nde karşılaştırma yapılacak bir örnek bulunamaması nedeniyle kuyunun tapınağa ait olabileceği düşünülmüştür. Buradan hareketle, Pausanius'un Aphrodite kültüne ait olarak söz ettiği su kuyusunun Bizans Dönemi'nde temizlenerek ve yükseltilerek kullanılmaya devam edilmiş olabileceği belirtilir (Erim, 1965, s. 136-137). Ancak konumu ve 
kot seviyeleriyle doğrudan kilisenin altarı ile ilişkili olduğu anlaşılan düzenlemenin thalassidion olduğu anlaşılmaktadır.

Patara Kent Bazlikası'nın (Antalya-Gelemiş) bema merkezinde dikdörtgen planlı altar kaidesi izleri tespit edilmiştir. Altarın üzerinde dört sütunla taşınan bir kyborion bulunduğu anlaşılır. Güneydoğu kyborion ayağının 0,55 m güneydoğusunda, altar ile synthronon arasında bir kuyu yer alır (Şekil 15-16). Kuyu iki kasnağın üst üste yerleştirilmesiyle oluşturulmuştur. Ölçülebilen derinliği 1,5 m olan kuyunun üst kasnağ 1 kare planlı ve merkezinde 0,52 m çapında dairesel ağızlıdır. Kasnak düzgün işlenmiş ve zımparalıdır. Kasnak kenarlarında herhangi bir halat izi yoktur. Kuyunun üst kasnak seviyesi, bemanın opus sectile döşemeli zemini ile aynı kottadır (Demirton, 2017, s.13). Kuyunun kilisenin işlevini yitirdikten sonraki dönemlere ait işliklerle ilişkili bir düzenleme olabileceği düşünülmüştür (İşkan ve diğerleri, 2015, s. 305). Kuyunun konumu, zemin döşemesiyle uyumu ve işçiliği göz önüne alındığında bemanın bir parçası olarak yapılmış olması muhtemeldir. Bu özellikleriyle ele alındığında thalassidion olarak tanımlanabilir.

\section{Değerlendirme ve Sonuç}

Thalassidionlar ayinlerden sonra altarın ve khalis, paten gibi tören esnasında kullanılan objelerin yıkanması için kullanılan su hazneleridir. Ekmek ve şarabın İsa'nın kanı ve etini sembolize etmesi göz önüne alındığında, liturjik kapların temizliğinin de aynı kutsal sembolizmden hareketle özenli bir niteliğe sahip olduğu düşünülmelidir.

Törensel yıkama ökaristi liturjisinin bir parçası olsa da tespit edilen thalassidion örneklerinin azlığı dikkat çeker. Kıbrıs, Kudüs, Kuzey Afrika ve Yunanistan'da birer örnek; Anadolu'da ise beş örnek karşımıza çıkar. Ancak kazı çalışmalarının devamlılığı ve bulguların tekrar değerlendirilmesiyle örneklerin artacağı öngörülebilir. Ayrıca, taşınabilir eserlerin thalassidion işlevinde kullanılmış olabileceği de gözardı edilmemelidir.

Arkeolojik olarak tespit edilen thalassidionların konumlarına bakıldığında en yaygın tercihin altarın doğusu olduğu görülür. Laodikeia Kilisesi ve Ksanthos Doğu Kilise'sinde su sağlayan künk sistemleri altarın doğu kenarıyla bağlantılıdır. Aphrodisias Kathedral Kilisesi'nde tespit edilen kuyu altarın doğu kenarındadır. Labraunda Doğu Kilisesi ve Kudüs Haç Manastırı Kilise'sinde su giderleri altarın doğusunda ancak kenar hattından mesafeli konumlanmıştır. Thalassidionların Lesvos Afentellis Kilisesi'nde altarın güneyinde, Kasr-el Kelb Kilisesi'nde batısında, Kourion Piskoposluk Kilisesi'nde güney batısında ve Patara Kent Bazilikası'nda ise güney doğusunda konumlandı̆̆ görülür.

Afentelli Kilisesi ve Kasr-el Kelb Kilisesi hariç diğer tüm örneklerde ortak özellik su giderinin bulunmasıdır. Su tahliyesi Ksanthos Doğu Kilisesi ve Laodikeia Kilisesi'nde pişmiş toprak künklerle; Labraunda Doğu Kilisesi'nde kanal vasıtasıyla; Kudüs Haç Manastırı, Patara Kent Bazilikası, Aphrodisias Kathedral Kilisesi ve Kourion Piskoposluk Kilisesi'nde ise kuyu ile sağlanmıştır. Su teminine yönelik veriler Ksanthos, Laodikeia ve Labraunda'da tespit edilmiştir. Üç kilisede de su pişmiş toprak künkler ile thalassidiona ulaştırılmıştır. Afentelli ve Kasr-el Kelb kiliselerinde sadece hazneler tespit edilmiştir. Su temini ve tahliyesinin nasıl sağlandığı bilinmemektedir. Hazne tespit edilen diğer örnek Laodikeia Konsil Kilisesi' dir. Her üçünde de hazneler küresel gövdeli, mermerden ve sadedir. 


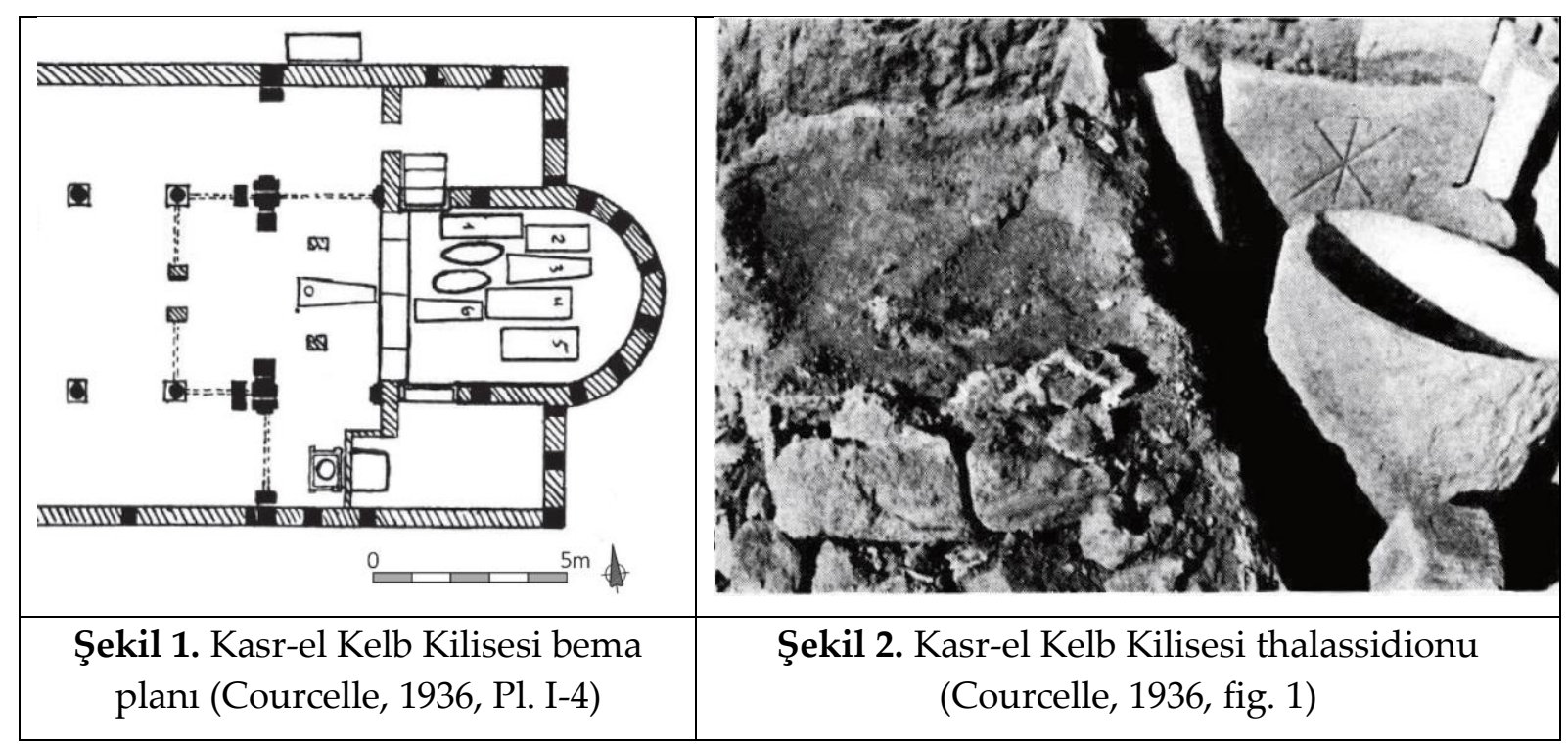

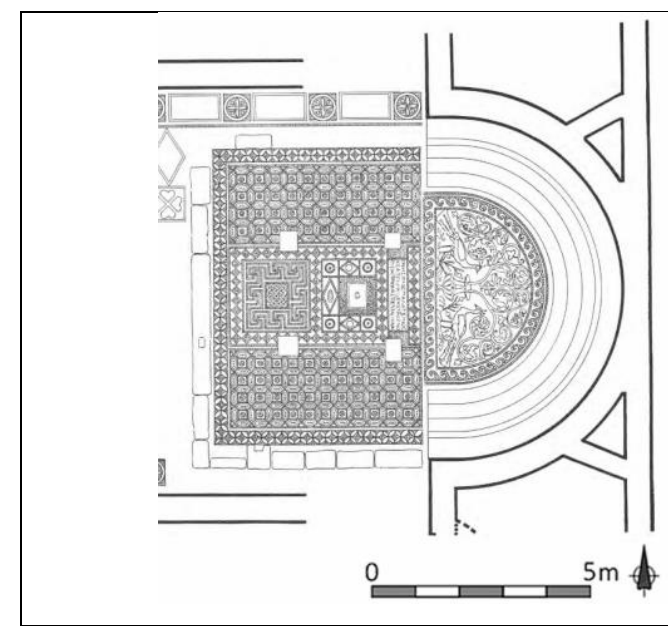

Şekil 3. Afentelli Bazilikası bema planı (Ooגávঠov, 1929, tl. III)

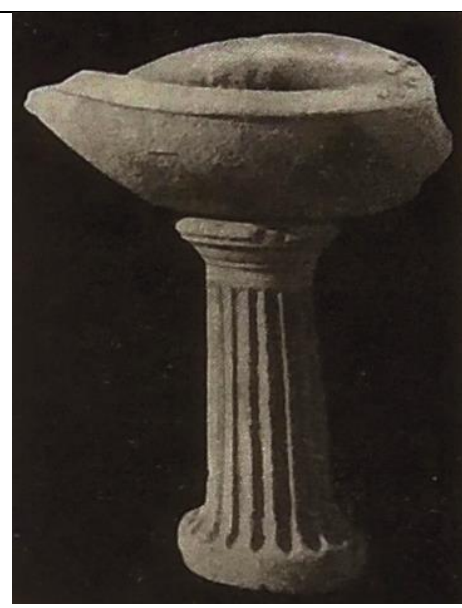

Şekil 4. Afentelli Bazilikası thalassidionu (Oo\ávঠov, 1929, fig. 78)

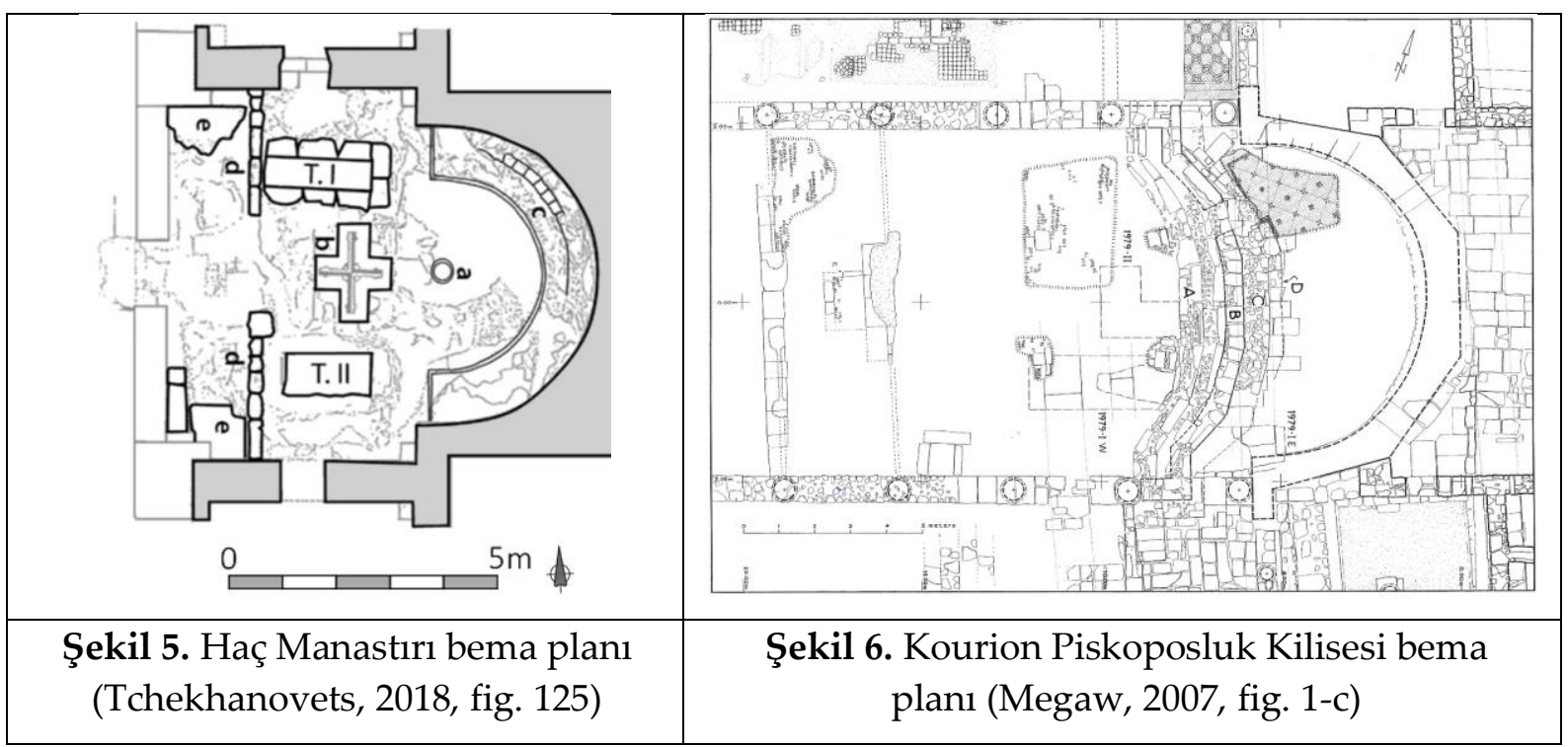



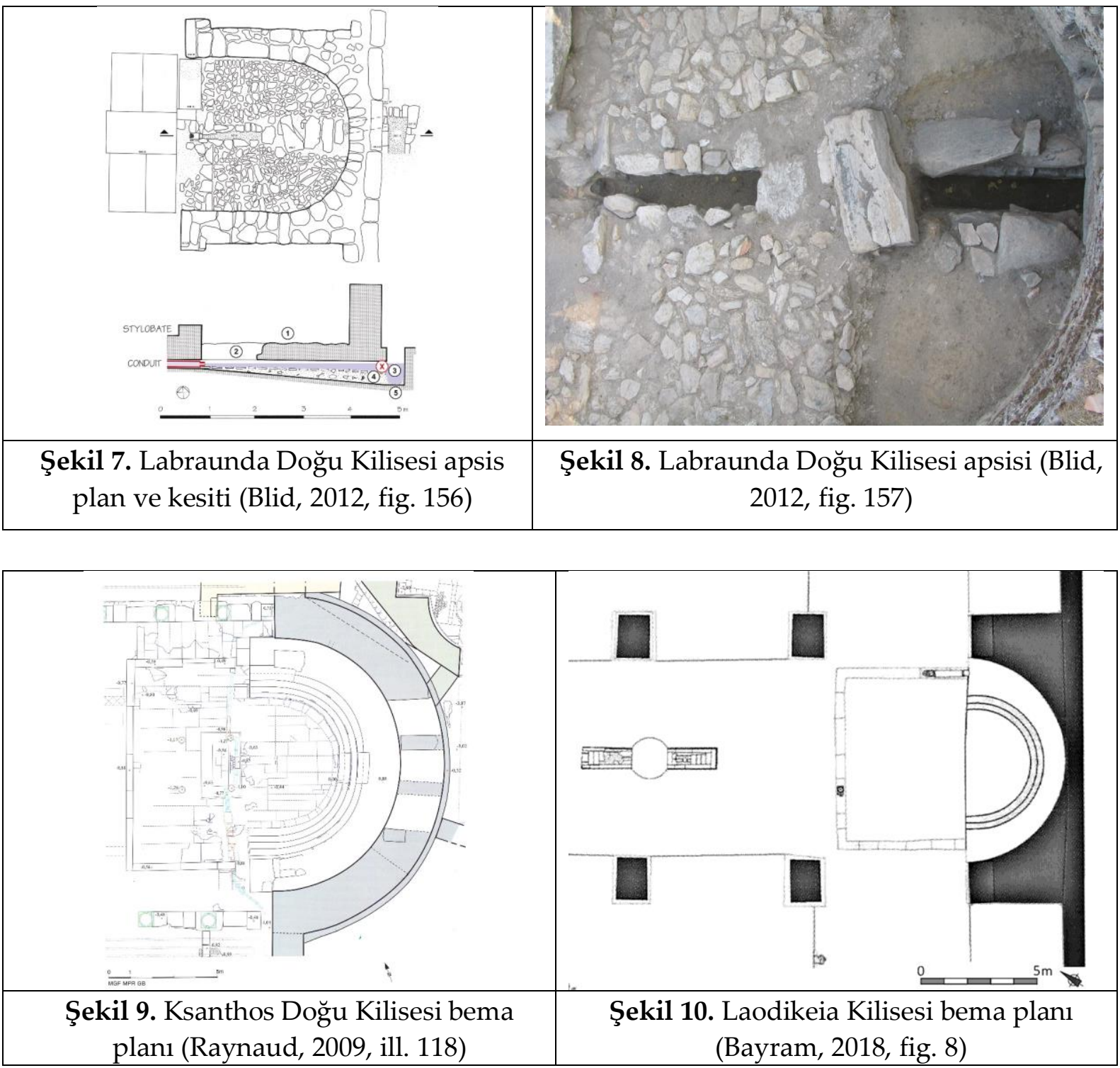

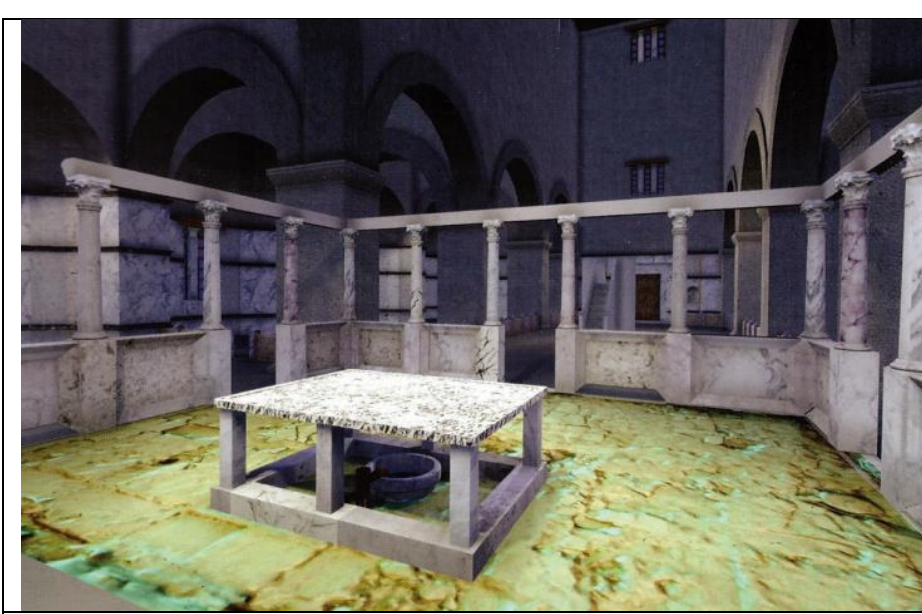

Şekil 11. Laodikeia Kilisesi bema canlandırması (Şimşek, 2015, res. 48)

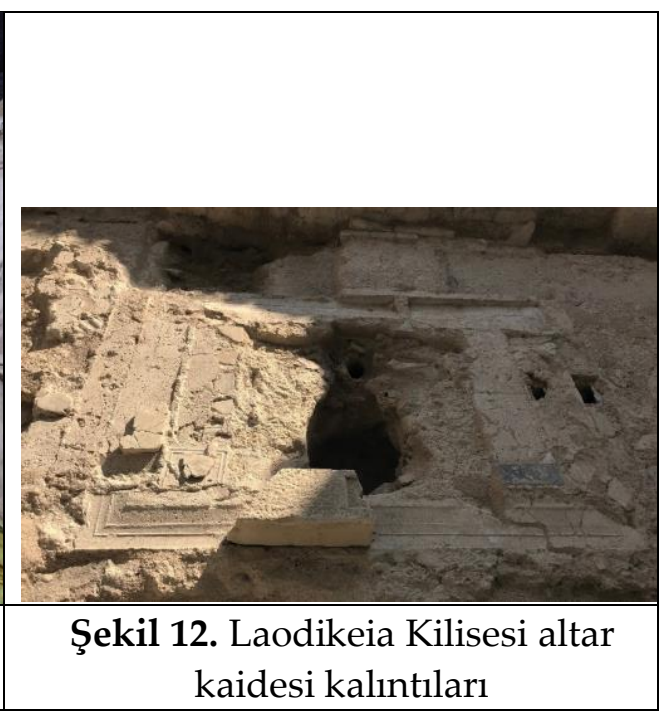

kaidesi kalıntıları 


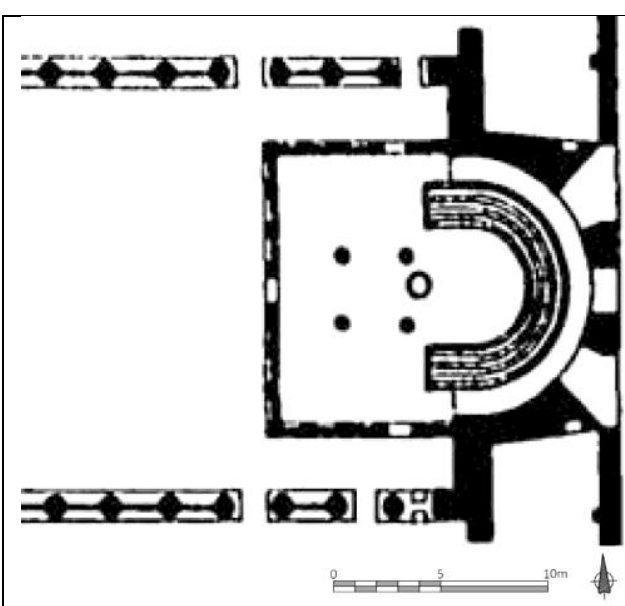

Şekil 13. Aphrodisias Kathedral Kilisesi bema planı (Hebert, 2000, pl. 17)

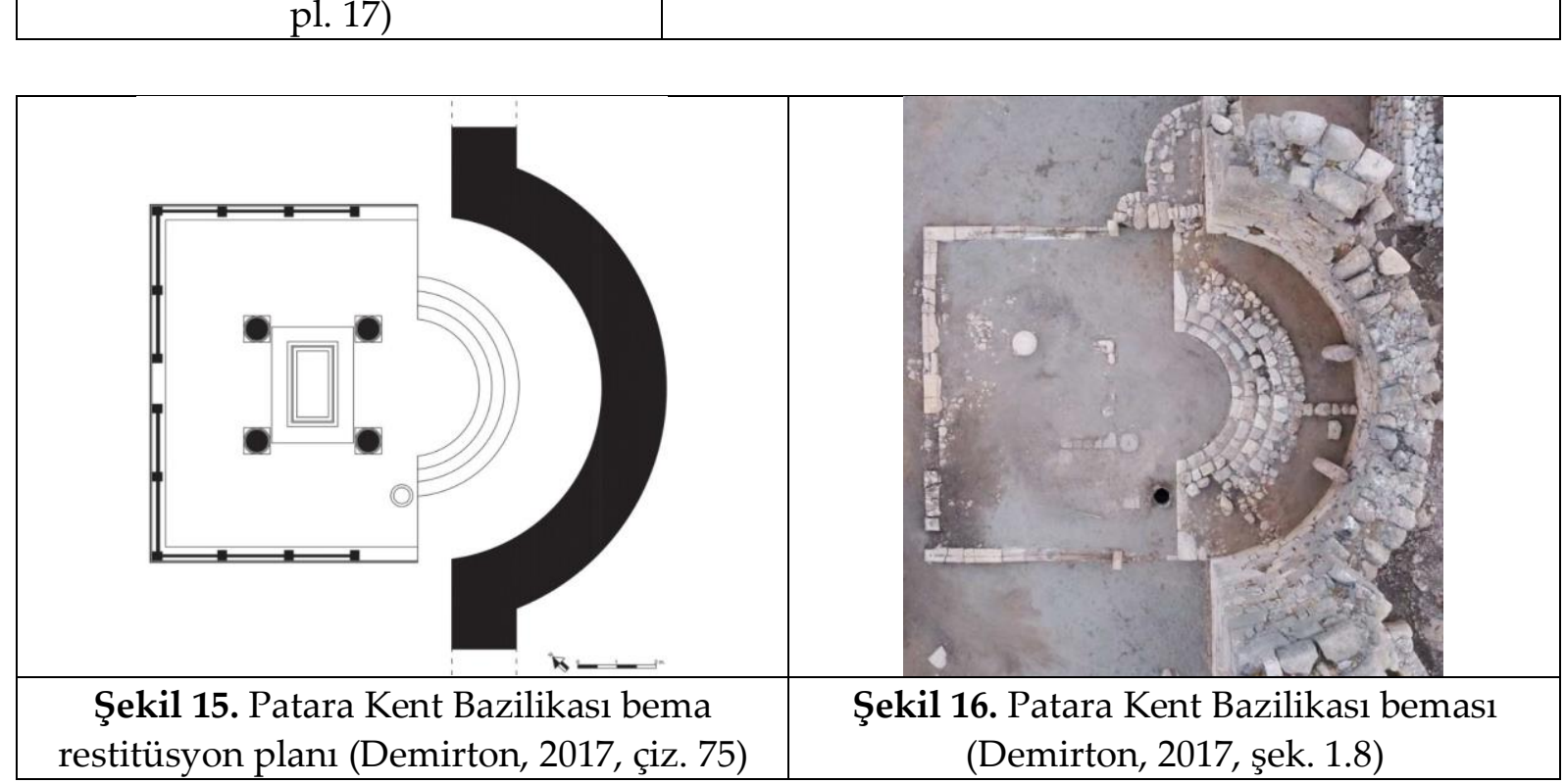

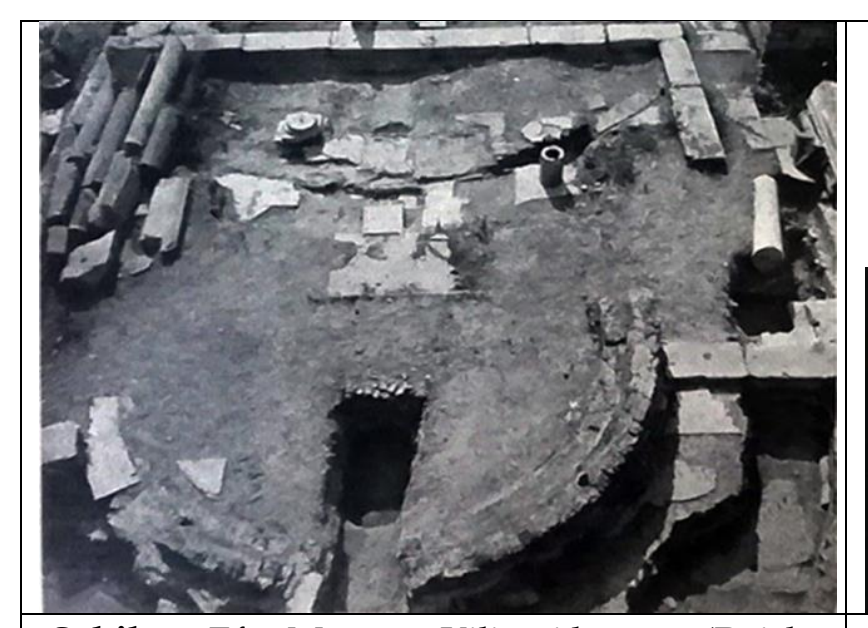

Şekil 17. Efes Meryem Kilisesi beması (Reich,

Knoll ve Keil, 1932, abb. 26)

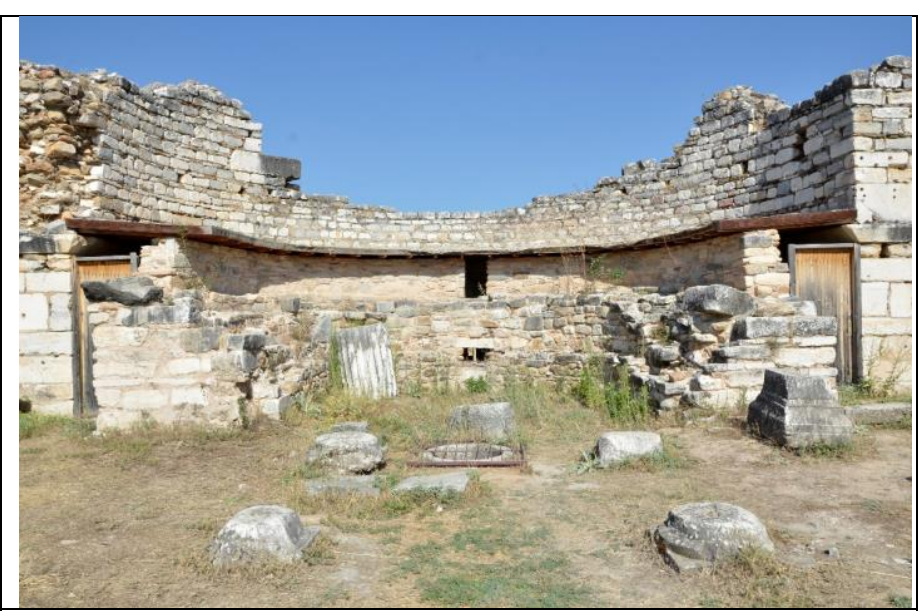

Şekil 14. Aphrodisias Kathedral Kilisesi beması

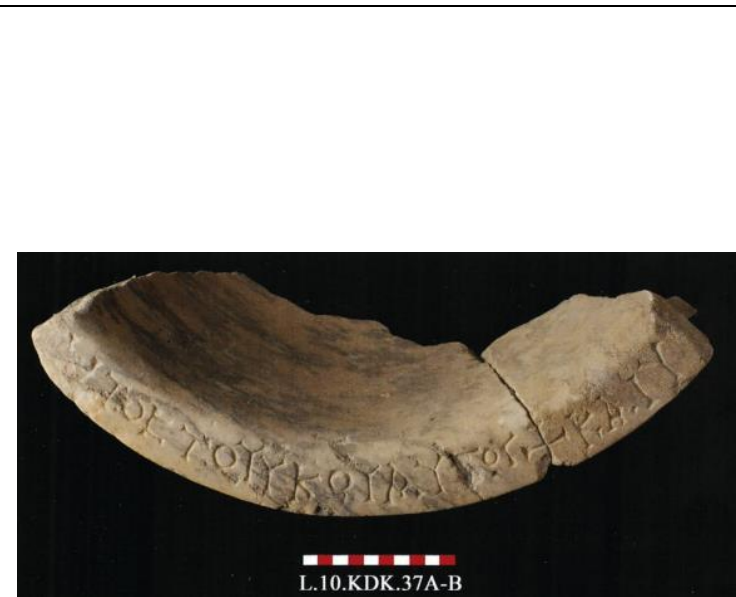

Şekil 18. Laodikeia Kilisesi thalassidionu (Şimşek, 2015, res. 50) 


\section{Kaynakça}

Acara, M. (1998). Bizans ortodoks kilisesinde liturji ve liturjik eserler. Hacettepe Üniversitesi Edebiyat Fakültesi Dergisi 15(1), 183-201.

Altripp, M. (2000). Bothros oder Thalassa und die frage nach der funktion der apsisnebenraume. Orthodoxes Forum 14, 63-71.

Aydın, A. (2006). Kilikia ve İsauria bölgesi vaftiz yapıları. Sanat Tarihi Dergisi 15(1), 1-19.

Aydın, A. (2012). Silifke Müzesi'nden figürlü bir duvar nişi bloğu. Olba XX, 408-425.

Bakırtzis, C. (2002). Pilgrimage to Thessalonike: the tomb of St. Demetrios. Dumbarton Oaks Papers 56, 175-192.

Berger, A. (1982). Das bad in der Byzantinischen Zeit. München: Institut für Byzantinistik und Neugriechische Philologie.

Blid, J. (2009). Late antique glass in sacred context: A hagiasma at Carian Labraunda. E. Laflı (Ed.) Late Antique/Early Byzantine Glass in the Eastern Mediterranean içinde (s. 133-150). İzmir: Tübitak.

Blid, J. (2012). Felicium temporum reparatio: Labraunda in late antiquity (c. AD 300-600). (Doctoral thesis, Universty of Stocholm, Stockholm).

Bogdanovic, J. (2017). The phiale as a spatial icon in the Byzantine cultural sphere. A. Lidov (Ed.) Holy water in the hierotopy and iconography of the Christian world içinde (373-392). Moscow: Theoria.

Broilo, F. A. (2009). Cleanses the sins with the water of the pure-flowing font: fountains for ablutions in the Byzantine Constantinopolitan context. Revue des Etudes Sud-Est Europeennes $47,5-24$.

Burkhardt, N. ve Wilson, M. (2013). The late antique synagogue in Priene: its history, architecture and context. Gephyra 10, 166-196.

Caseau, B. (2007). Ordinary objects in Christian healing sanctuaries. L. Lawan (ed.) Late Antique Archaeology 5 Objects in Context Object in Use içinde (s. 625-654). Boston: Brill.

Ćurčić, S. (2010). Architecture in the Balkans: from Diocletian to Süleyman the magnificent. New Haven and London: Yale Universty.

Çelebi, E. (2008). Bulunduğu bölgeye ve yapılara adını veren su "ayazma" ve mimariye etkisi. A. G. Küçükkaya ve diğerleri (Ed.) IV. Uluslararası Mimar Sinan Sempozyumu Su ve Mimarlık, 10-11 Nisan 2008, Edirne, Türkiye, Bildiriler içinde (s. 37-42). Edirne: Trakya Üniversitesi Mühendislik-Mimarlık Fakültesi.

Demirton, C. (2017). Patara Kent Bazilikası Liturjik Taş Eserleri. (Doktora tezi, Akdeniz Üniversitesi, Antalya).

Des Courtils, J. ve Laroche, D. (1999). Xanthos - le Letoon: raport sur la campagne de 1998. Anatolia Antiqua 7, 367-399.

Doğan, S. (2001). Bizans mimarliğinda liturjik işlevli taş yapılarda terminoloji sorunu. M. S. Pekak (Ed.) Sanat Tarihinde Terminoloji Sorunları Semineri I (Mimari ve Mimari Sisleme), 23-24 Kasım 2001, Ankara, Türkiye içinde (s. 31-42). Ankara: Hacettepe Üniversitesi. 
Doğan, S. (2019). Mimari plastik buluntular: liturjik kuruluşlar ve mekanlar ile ilişkisi. S. Doğan ve E. F. Fındık (Ed.) Aziz Nikolaos Kilisesi Kazıları 1989-2009 içinde (s. 301-328). İstanbul: Homer.

Ebersolt, J. (1910). Sainte-Sophie de Constantinople: étude de topographie d'apres les cérémonies. Paris: Ernest Leroux.

Eusebius Historia Ecclesiae. Çev. McGiffert A. C. (1890). Eusebius: church history from A.D. 1-324. A select library of nicene and post-nicene fathers of the christian church, Second Series Volume I: Eusebius: Church history, Life of Constantine the great, and oration in praise of Constantine. P. Schaff (Ed.) içinde (s. 1-402) Newyork: Christian Literature Publishing Company.

Erim, K. T. (1965). Aphrodisias 1964 hafriyatı. Türk Arkeoloji Dergisi 14(1-2), 135-140.

Foss, C. (2002). Pilgrimage in medieval Asia Minor. Dumbarton Oaks Papers 56, 153-173.

Grossmann, P. (2001). Christliche architektur in Ägypten. Handbook of Oriental Studies Section 1 The Near and Middle East 62. Leiden-Boston-Köln: Brill.

Gsell, S. (1901). Les monuments antiques de L'Algeria (tome second). Paris: Service des Monuments Historiques de L' Algeria.

Gürbüzer, M. (2017). Aigai'den bir bothros. Arkeoloji Dergisi XXII, 245-262.

Hassett, M. (1911). Presbytery. C. D. Herbermann ve diğerleri (Ed.) The Catholic Encyclopedia içinde (Cilt XII, s. 395) New York: Robert Appleton Company.

Hebert, L. (2000). The temple-church at Aphrodisias. (Doctoral thesis, Universty of Newyork, New York).

İşkan, H., Aktaş, Ş., Polat-Becks, A., Becks, R., Ceylan, B., Dündar, E., Erdoğan, O., Erkoç, S., Kızıltaş, H., Koçak, M., Orhan, S., Schuler, C., Varmaz, Ş., Varmaz, D., Yirşen, Ş. Ve Zimmermann, K. (2015). Patara 2013 Kazıları. Anadolu 41, 299-322.

Karakaya, E. (1993). Ayazmalar. İ. Tekeli ve diğerleri (Ed.) Dünden Bugüne İstanbul Ansiklopedisi içinde (Cilt 1, s. 472-474). İstanbul: Türkiye Ekonomik ve Toplumsal Tarih Vakfı.

Khatchatrian, A. (1982). Origine et typologie des baptisteres paleochretiens. Mulhouse: Centere de Culture Chretienne.

Loosley, E. (2012). The architecture and liturgy of the bema in fourth- to sixth-century Syrian churches. Leiden-Boston: Brill.

Magdalino, P. (1990). Church, bath and diakonia in medieval Constantinople. R. Morris (Ed.) Church and People in Byzantium 20th Spring Symposium of Byzantine Studies içinde (s. 165-190). Birmingam: University of Birmingam Centre For Byzantine, Ottoman and Modern Greek Studies.

Mathews, T. (1971). The early churches of Constantinople: architecture and liturgy. London: Pennsylvania University.

McCormick, M. (1991). Annointing. A. Kazhdan ve diğerleri (Ed.) Oxford Dictionary of Byzantium içinde (Cilt 1, s. 107) NewYork-Oxford: Oxford Universty.

Megaw, A. H. S. (2007). Kourion excavations in the episcopal precinct. Washington: Dumbarton Oaks. 
Montserrat, D. (1998). Pilgrimage to the shrine of SS Cyrus and John at Menouthis in late antiquity. D. Frankfurter (Ed.) Pilgrimage and Holy Space in Late Antique Egypt içinde (s. 257280) Leiden: Brill.

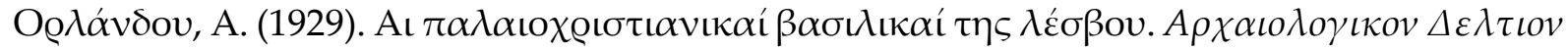
$12,1-72$.

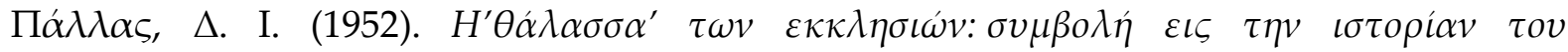

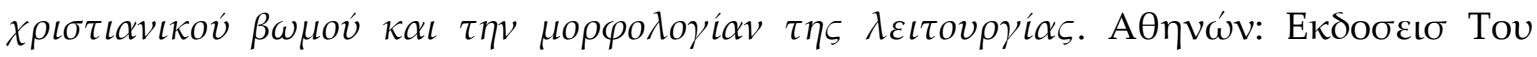

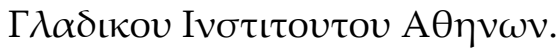

Pitarakis, B. (2015). Işık, su ve acaibü'l mahlukat: doğaüstü şifa güçleri. B. Pitarakis (Ed.) Hayat Kısa Sanat Uzun Bizans'ta Şifa Sanatı içinde (s. 42-63). İstanbul: Pera Müzesi.

Raynaud, M. P. (2009). Corpus of the mosaics of Turkey volume 1 Lycia Xanthos part 1 the east basilica. Istanbul: Uludağ Üniversitesi Mozaik Araştırmaları Merkezi.

Ristow, S. (1998). Frühchristliche baptisterien. Jahrbuch für Antike und Christentum Erganzungsband 27. Münster: Aschendorffesche.

Reich, E., Knoll, F. ve Keil, J. (1932). Die marien kirche in Ephesos. Forchungen in Ephesos IV(1). Wien: Österreichisches Archäologisches Institut.

Ruggieri, V. (2017). The water in the basin (embates, loutron) and Byzantine euchology. Studi sull'Oriente Cristiano 21(2), 303-321.

Şimşek, C. (2015). Laodikeia Kilisesi Lykos Vadisinde Hıristiyanlık. Denizli: Denizli Büyükşehir Belediyesi.

Talbot, A. M. (2002). Pilgrimage to healing shrines: the evidence of miracle accounts. Dumbarton Oaks Papers 56, 153-173.

Taft, R. F. (1991a). Communion. A. Kazhdan ve diğerleri (Ed.) Oxford Dictionary of Byzantium içinde (Cilt 1, s. 491) NewYork-Oxford: Oxford Universty.

Taft, R. F. (1991b). Anaphora. A. Kazhdan ve diğerleri (Ed.) Oxford Dictionary of Byzantium içinde (Cilt 1, s. 85) NewYork-Oxford: Oxford Universty.

Taft, R. F. ve Bouras, L. (1991). Altar. A. Kazhdan ve diğerleri (Ed.) Oxford Dictionary of Byzantium içinde (Cilt 1, s. 71) NewYork-Oxford: Oxford Universty.

Tchekhanovets, Y. (2018). The caucasian archaeology of the holy land: Armenian, Georgian and Albanian communities between the fourth and eleventh centuries CE. Leiden ve Boston: Brill.

Teteriatnikov, N. B. (1996). The liturgical planning of Byzantine churches in Cappadocia. Orientalia Christiana Analecta 252, Roma: Pontificio Istituto Orientale.

Wiegand, T. ve Shrader, H. (1904). Priene ergebnisse der ausgrabungen und untersuchungen in den jahren 1895-1898. Berlin: Reimer.

Yazıcı, S. U. (2018). Geç antik çağ ve erken Hıristiyanlık dünyasında dinsel su inanışları. Trakya Üniversitesi Edebiyat Fakültesi Dergisi 8(16), 21-31.

\footnotetext{
Açıklamalar

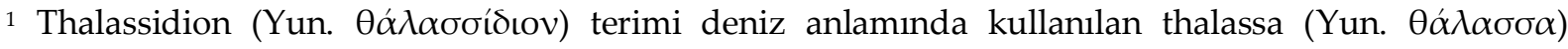
kökünden üretilmiştir. Yayınlarda thalassa ve thalassidion olarak her iki şekilde de kullanıldığı görülür.
} 
Ancak, mimari bir düzenleme ifade edilirken thalassidion şeklinde kullanmak daha doğru ve anlaşlır olacaktır.

${ }^{2}$ Bothros (Yun. ßóӨ@os) kelime anlamıyla hendek ya da çukur demektir. Antik dönemde kurban törenleriyle ilişkili sunular için kullanılmışlardır. Ritüele göre kurban kanı bothrosa dökülür. Törensel yemekten sonra da kurbandan arta kalanlar bothrosa bırakılır. Son olarak şarap, su, süt ve bal kullanılarak libasyon gerçekleştirilir (Gürbüzer, 2017, 64-74). D. J. Pallas, kiliselerdeki mezarla ilişkili çukurların şarap, su, süt, zeytinyağı gibi sıvı sunumlarıyla ilişkili olması gerektiğini savunur. Yazılı kaynaklardan yola çıkarak, yerel uygulamalar olarak bazı merkezlerde antik geleneklere göre sunu

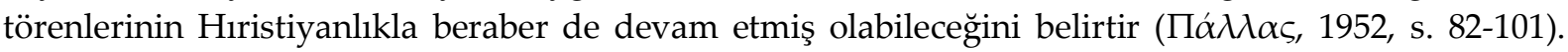
Ancak işlevsel olarak farklı olan, mimaride de ayrı ayrı ortaya çıkan bothros ve thalassidion arasında ayrım yapmak gerekir. Törensel temizlik ile ilişkili olan düzenlemelerin thalassidion, sunular için kullanılan çukurların bothros olarak tanımlanması daha uygun olacaktır (Altripp, 2000, s. 68-69). Bu nedenle bothros ile ilgili olabileceği düşünülen düzenlemeler bu makalenin kapsamı dışında tutulmuştur.

${ }^{3}$ D. J. Pallas tarafından thalassidion olabileceği belirtilen (Пó $\lambda \lambda \alpha \varsigma, 1952$, s. 9-10) Stobi Piskoposluk Kilisesi altarı altındaki haznenin röliker olduğu anlaşılmıştır (Ćurčič, 2010, s. 163).

Benzer bir şekilde Cezayir Seriana'daki kilisenin altarı altındaki hazne D. J. Pallas tarafından

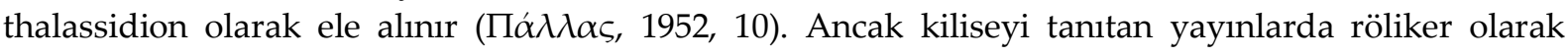
tanımlanmıştır (Gsell, 1901, s. 254).

Priene Sinagogu'nda apsis nişi önünde 0, $55 \mathrm{~m}$ yüksekliğindeki yivli sütun üzerinde yer alan 0, $95 \mathrm{~m}$ çapında mermer bir su teknesi yer alır (Burkhardt ve Wilson, 2013, s. 173). Ancak yapı ilk yayınlandığında ev kilisesi olarak tanıtılmıştır (Wiegand ve Shrader, 1904, s. 480-481). Bu nedenle D. J.

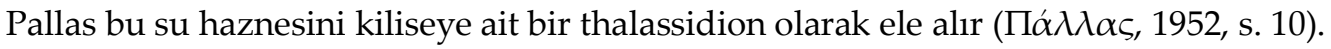

Suriye Qirq Bizeh Kilisesi avlusunda bir haznesi yer alır (Loosley, 2012, s. 229). D. J. Pallas bu kilise hakkında haznenin konumunun belirtilmediği yayınlardan yola çıkarak su haznesinin thalassidion

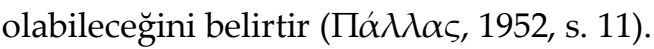

Efes Meryem Kilisesi kazı sonuçlarına ait yayınlarda, altarın kuzey kenarı yanında üst kısmı hazne biçiminde oyulmuş dairsel kesitli bir mermer parça görülür (Şekil 17). Ancak yayında bu parça ele alınmamış ve hakkında bilgi verilmemiştir (Reich, Knoll ve Keil, 1932, s. 32). D. J. Pallas, haznenin insitu olması durumunda thalassidion olarak değerlendirilmesi gerektiğini belirtir (Пó $\lambda \lambda \alpha \varsigma, 1952$, s. 10).

${ }^{4}$ Bazı Türkçe çevirilerde su referansı anlaşılmamaktadır. Ancak Yeşeya 12:3'te geçen Yunanca "k $\alpha \grave{~}$

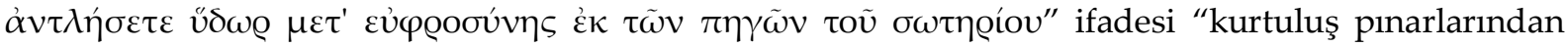
sevinçle su alacaksınız" şekinde çevrilmelidir.

${ }^{5}$ Kelime adak/sunu anlamındadır. Ökaristi ayininde altara getirilen ekmek ve şarabın kutsanmasını ifade eder. 6. yüzyıldan itibaren kutsama için okunan dua da aynı adla anılır (Taft, 1991b, 85).

${ }^{6}$ Kiliselerde törenlere katılan yaşlı ya da yüksek rütbeli din adamları için ayrılmış bölüm (Hassett, 1911, 395). 